\title{
Possible Impacts of New Accuracy Standards of Self-Monitoring of Blood Glucose
}

\author{
Satish K Garg, MD, ${ }^{1}$ Kathryne Reed, BA, ${ }^{2}$ Jessica Grey, BA ${ }^{2}$ and Alex Westerman, BA ${ }^{2}$
}

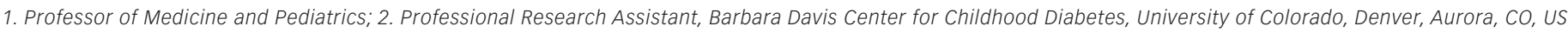

\begin{abstract}
Self-monitoring of blood glucose (SMBG) was an integral part of reduction of complication rates in the landmark Diabetes Control and Complications Trial (DCCT) in Type 1 diabetes. However, the accuracy and standardized reporting of SMBG devices remains a key concern, with the 2003 version of International Organization for Standardization (ISO) 15197 standards allowing for $5 \%$ of readings to fall outside of the acceptable ranges. A recently revised 2013 version of the ISO 15197 standards includes stricter accuracy standards, with a 36-month transition period recommended before compliance becomes mandatory. These new accuracy standards will have implications not only for manufacturers of currently available and future devices but also for the end-users, who may face rising costs and necessary measures to improve patient error rates associated with SMBG in routine clinical practice.
\end{abstract}

\section{Keywords}

Type 1 diabetes, Type 2 diabetes, self-monitoring of blood glucose, accuracy, performance, ISO 15197

\begin{abstract}
Disclosures/conflicts of interest: Satish K Garg has received research funding from Medtronic, Sanofi, JAEB Center, National Institutes of Health (NIH), Halozyme, MannKind Corp, Eli Lilly \& Co, and Novo Nordisk; has served as a consultant/advisor for Medtronic, Sanofi, Valeritas, Novo Nordisk, Johnson \& Johnson, and Roche Diagnostics; and has received honoraria from Medtronic, Roche Diagnostics, Valeritas, Novo Nordisk, and Johnson \& Johnson. Kathryne Reed, Jessica Grey, and Alex Westerman have no conflicts of interest to declare. None of the authors received remuneration for the development of this article.

Acknowledgments: Medical writing/editorial assistance was provided by Kimberly Brooks, PhD, of SciFluent and was funded by Nipro Diagnostics.

Received: March 27, 2013 Accepted: April 3, 2013 Citation: US Endocrinology, 2013;9(1):16-9 DOl: 10.17925/USE.2013.09.01.16

Correspondence: Satish K Garg, MD, Barbara Davis Center for Childhood Diabetes, University of Colorado - Denver, 1775 Aurora Court, Aurora, CO 80045 , US.

E: satish.garg@ucdenver.edu
\end{abstract}

Support: The publication of this article was supported by Nipro Diagnostics. The views and opinions expressed are those of the authors and not necessarily those of Nipro Diagnostics.

Recently, the International Diabetes Federation (IDF) estimated 371 million individuals are living with diabetes worldwide, including $50 \%$ who remain undiagnosed. ${ }^{1}$ The prevalence of diabetes is increasing in every country, and is estimated to cross the half-billion mark by $2030 .{ }^{2}$ In 2012, worldwide diabetes healthcare expenditure was estimated at $\$ 471$ billion, ${ }^{1}$ and in the US was estimated at $\$ 245$ billion (a $41 \%$ increase over the past 5 years). ${ }^{3}$

Intensive diabetes management is essential for preventing or delaying microand macrovascular complications of this disease. According to the Diabetes Control and Complications Trial (DCCT), achieving better glucose control was facilitated by frequent self-monitoring of blood glucose (SMBG). ${ }^{4}$ The DCCT found that intensive therapy of Type 1 diabetes (insulin administered $\geq 3$ times/ day by injection or external pump along with SMBG performed $\geq 4$ times/day) significantly reduced the risks of new-onset retinopathy by $76 \%$ and slowed retinopathy progression by $54 \%$ compared with conventional therapy (i.e. one to two insulin injections with daily SMBG or urine testing). Longer-term follow-up (mean of 17 years) of DCCT patients in the Epidemiology of Diabetes Interventions and Complications study also showed significant reduction of macrovascular events among patients who had received intensive therapy. ${ }^{5}$ Despite documented long-term success of tight glycemic control in Type 1 diabetes ${ }^{4}$ real-world self-management remains poor, as illustrated by low daily (39\%) and routine (67\%) rates of SMBG in a Danish-British survey of $>1,000$ patients with Type 1 diabetes. ${ }^{6}$ In a recent analysis of the T1D
Exchange Clinic Registry, which included $>13,000$ pediatric patients aged $<20$ years with a history of Type 1 diabetes for $\geq 1$ year, most participants failed to attain specified A1C targets ( $<7.5 \%$ to $<8.5 \%$ ); however, achievement of this goal was highest among the youngest patients ( $64 \%$ for patients aged 1 to $<6$ years versus $43 \%$ for ages 6 to $<13$ years and $21 \%$ for ages $13-20$ years). ${ }^{7}$ A second analysis from the T1D Exchange Clinic Registry demonstrated a direct relationship between SMBG frequency and A1C values, regardless of age or use of insulin pump versus injection. 8,9

In contrast to the Type 1 diabetes population, the role of SMBG for patients with noninsulin-treated Type 2 diabetes is highly controversial, promoting substantial discussion, debate, and the conduct of numerous prospective and retrospective studies as well as meta-analyses to address this matter. ${ }^{10-27}$ Overall, randomized controlled trials have yielded mixed results as to whether SMBG improves glycemic control in noninsulin-treated patients with Type 2 diabetes. ${ }^{18,21-27}$ Systematic reviews and meta-analyses have demonstrated a consistently small (about 0.2-0.3 \%) but statistically significant SMBG-derived improvement in A1c control among patients with Type 2 diabetes; however, the clinical relevance of such a modest improvement has been questioned, especially from a cost-benefit standpoint. 11,12,28,29 In a US cost-effectiveness model, 40-year risks for 14 of 16 evaluated types of complications favored the use of SMBG (one to three times/day versus no SMBG) in patients with Type 2 diabetes receiving oral antidiabetic therapy. ${ }^{16}$ 
Table 1: ISO 15197 Accuracy Standards for SMBG Devices

\begin{tabular}{|c|c|c|}
\hline & ISO $15197: 2003^{40}$ & ISO $15197: 2013 * 41$ \\
\hline $\begin{array}{l}\text { Minimum accuracy } \\
\text { criteria }\end{array}$ & $\begin{array}{l}95 \% \text { of readings: } \\
\text { (1) within } \pm 20 \% \\
\text { of the reference } \\
\text { for glucose levels } \\
>75 \mathrm{mg} / \mathrm{dL} \text {; (2) within } \\
\pm 15 \mathrm{mg} / \mathrm{dL} \text { of the } \\
\text { reference for glucose } \\
\text { levels } \leq 75 \mathrm{mg} / \mathrm{dL}\end{array}$ & $\begin{array}{l}95 \% \text { of readings: } \\
\text { (1) within } \pm 15 \% \\
\text { of the reference } \\
\text { for glucose levels } \\
\geq 100 \mathrm{mg} / \mathrm{dL} \text {; (2) within } \\
\pm 15 \mathrm{mg} / \mathrm{dL} \text { of the } \\
\text { reference for glucose } \\
\text { levels }<100 \mathrm{mg} / \mathrm{dL}\end{array}$ \\
\hline $\begin{array}{l}\text { Specifications for } \\
\text { outliers }\end{array}$ & None & $\begin{array}{l}99 \% \text { of readings } \\
\text { within zones A and } \\
\text { B of the Consensus } \\
\text { Error Grid for Type } 1 \\
\text { diabetes }\end{array}$ \\
\hline $\begin{array}{l}\text { Number of reagent } \\
\text { lots required for } \\
\text { testing }\end{array}$ & 1 & 3 \\
\hline
\end{tabular}

Current American Diabetes Association (ADA) recommendations call for frequent SMBG for patients on multiple-dose insulin or insulin pump therapy. ${ }^{30}$ Per expert consensus or clinical experience of the panel, when SMBG is used as a component of broader education for patients administering less frequent insulin injections or non-insulin therapies, it may be helpful for guiding treatment decisions and/or patient self-management.

Personal ('realtime') continuous glucose monitoring (CGM) was developed with the goal of identifying both hyperglycemic and hypoglycemic trends, allowing for timely therapeutic adjustments. ${ }^{31,32}$ The first US Food and Drug Administration (FDA) approval of a realtime CGM device was granted in 1999 (GlucoWatch Biographer, Cygnus Inc, Redwood City, CA, which had a number of shortcomings and is no longer manufactured), with several other personal CGM devices (e.g. Navigator, Abbott Diabetes Care, Alameda, CA; Medtronic, Northridge, CA; DexCom, San Diego, CA) subsequently approved. ${ }^{32}$ The ADA 2013 clinical practice guidelines recognize the potential for CGM plus intensive insulin therapy to reduce A1c in selected adults (aged $\geq 25$ years) with Type 1 diabetes, citing the highest level of evidence (i.e. from well-conducted, generalizable, randomized controlled trials). ${ }^{30}$ Lower-level evidence suggests CGM may also benefit younger patients, and expert consensus supports a supplemental role in patients with hypoglycemia unawareness and/or frequent hypoglycemia. ${ }^{30}$

Multiple reports demonstrate incidents of dangerous overnight hypoglycemia and postprandial hyperglycemia detectable with CGM, but normally missed by SMBG. ${ }^{33}$ Given calibration of currently available CGM systems is reliant on $\mathrm{SMBG}^{34}$ it is important to note that CGM is currently approved as an adjunctive device only. ${ }^{35}$ The dependency of CGM technology on SMBG makes the accuracy of SMBG values of even greater importance as CGM becomes standard of care. ${ }^{34}$

\section{Accuracy of SMBG Devices}

Traditionally, the concept of SMBG accuracy captures how close an average of readings is to a reference value, not how closely or how many of the

\section{Figure 1: Consensus Error Grid and Zone Definitions ${ }^{41}$}

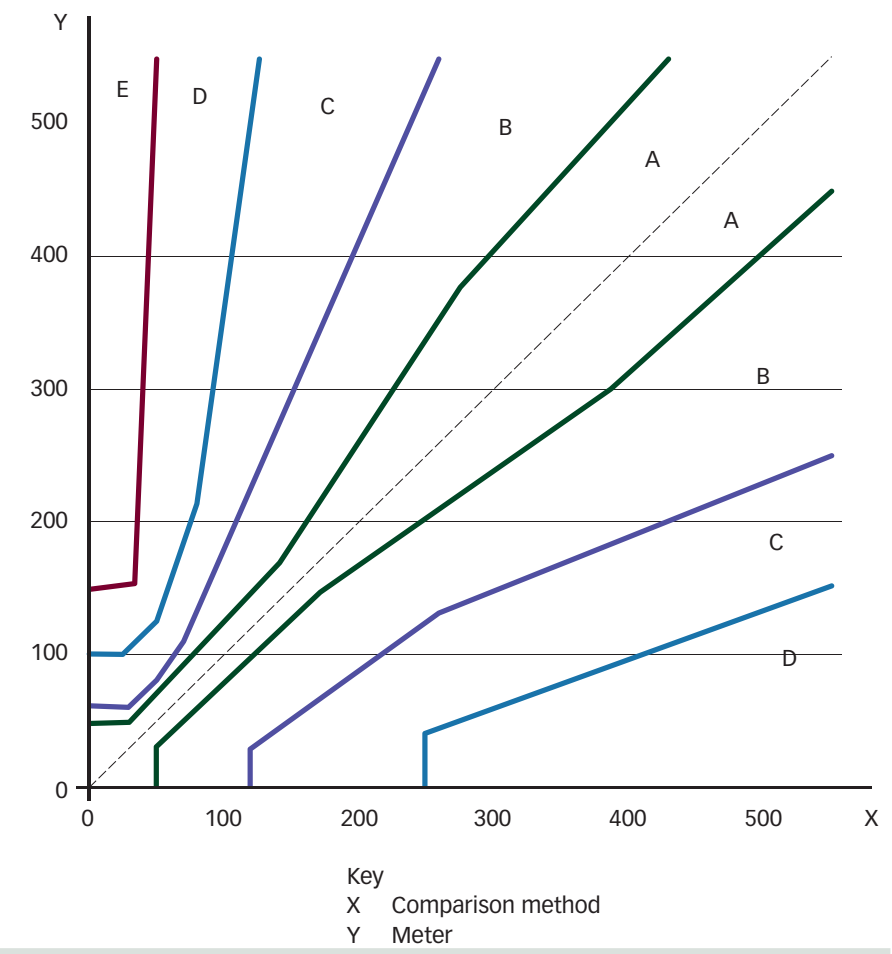

Risk Level Risk to Patient with Diabetes

(CEG zone)

A No effect on clinical action

B Altered clinical action - little or no effect on clinical outcome

C Altered clinical action - likely to affect clinical outcome

D Altered clinical action - could have significant medical risk

E Altered clinical action - could have dangerous consequences

The five zones ( $A, B, C, D$, and E) of the Consensus Error Grid (CEG) are defined by estimated patient risk. International Organization for Standardization (ISO) 2013 - all rights reserved. This figure is reproduced International Organization for Standardization (ISO) 2013 - all rights reserved. This figure is reproduced
from ISO/Final Draft International Standard (FDIS) 15197 with permission of American National Standards Institute (ANSI) on behalf of ISO. This is a draft ISO document that is subject to change without notice and cannot be referred to or relied upon as an ISO standard.

individual readings equate to the reference value. ${ }^{36} \mathrm{~A}$ number of accuracy standards have been proposed over the years. The ADA proposed standards for SMBG device accuracy as early as 1987,, ${ }^{37}$ when they recommended total error (i.e. analytical plus user error) be $<10 \%$ for $100 \%$ of glucose concentrations 30 to $400 \mathrm{mg} / \mathrm{dL}^{38}$ In 1996, with recognition of the crucial role of SMBG in the improved outcomes achieved in the DCCT, the recommendation was revised to support a maximum analytical error $\leq 5 \% .{ }^{39}$ Subsequently, a collaborative effort involving the International Organization for Standardization (ISO), international regulatory authorities, healthcare providers, and SMBG manufacturers established minimum accuracy standards for SMBG devices (known as the ISO 15197 criteria), originally released in $2003^{40}$ and recently updated for $2013^{41}$ (see Table 1). The major critique of the ISO 15197:2003 guidelines, which had been adopted by the FDA and other regulatory authorities, is that the $5 \%$ (or one in 20) threshold was too high and therefore allowed for too many large, medically unacceptable errors. ${ }^{37,42}$ In the 2013 revision, this matter was addressed by 


\section{Table 2: Factors Influencing the Accuracy of SMBG Devices $34,36,55$}

\begin{tabular}{ll} 
Strip Factors \\
\hline - & Lot-to-lot variability \\
- & Changes in enzyme coverage \\
- & Improction of the mediator for electrochemical blood glucose strips \\
& with an open vial) \\
- & Relatively short shelf-life, with expiration dates generally $\sim 2$ years \\
& under ideal conditions
\end{tabular}

Physical/Environmental Factors

- Influence of high and low temperatures

- Influence of high altitude

- $\quad$ Oxygen concentration for glucose oxidase biosensor strips

\section{Patient Factors}

- $\quad$ Miscoding of the device (ameliorated by some newer devices that avoid coding)

- $\quad$ Variations in hematocrit

- $\quad$ Patient error (e.g. improper technique, improper device, or test strip storage, and erroneous reading or interpretation of results)

- $\quad$ Contaminants from poor hand washing

- Interfering physiologic substances (e.g. triglycerides, oxygen, and uric acid)

Pharmacologic/Treatment Factors

- Medications interfering in electrochemical glucose oxidase systems (e.g. acetaminophen, L-dopa, tolazamide, and ascorbic acid)

- Medications interfering with glucose dehydrogenase (e.g. icodextrin, which is a component of some peritoneal dialysis fluids)

- $\quad$ Oxygen therapy

a new requirement to address outliers, requiring that $99 \%$ of readings fall within zones A and B of the survey-derived Consensus Error Grid for Type 1 diabetes (see Figure 1). ${ }^{41}$

There has been an increasing amount of published literature characterizing the relative accuracy of commonly used $\mathrm{SMBG}^{43-50}$ and $\mathrm{CGM}^{31,51,52}$ systems. One study evaluated the accuracy of 27 SMBG devices according to the ISO 15197:2003 criteria and found that >40 \% of evaluated systems yielded results for concentrations $\geq 75 \mathrm{mg} / \mathrm{dL}$ that failed to meet the requirement of $\geq 95 \%$ concentrations within $\pm 20 \%$ of the reference method. ${ }^{43} \mathrm{~A}$ second large study found seven of 34 (21\%) assessed SMBG failed to meet the ISO 15197:2003 criteria. ${ }^{49}$

In March 2010, the FDA/Center for Devices and Radiological Health held a public meeting on blood glucose monitors, prompted by ongoing questions from the clinical and patient communities surrounding acceptability of accuracy standards and requests for stricter FDA performance standards. This renewed attention on SMBG device accuracy stems from concerns about detecting hypoglycemia and the failure of achieving A1c targets, and other factors such as an emerging role for SMBG in hospital intensive care units. The FDA meeting conclusions highlighted the need for better analytical and clinical performance of SMBG devices, and methods to address the 'human factor errors' known to influence SMBG readings. ${ }^{53}$ As one of the specific outcomes of this meeting, it was anticipated that the FDA would move away from the ISO 15197:2003 criteria in favor of tighter standards.

The new ISO 15197:2013 standards are not the only accuracy standards that have been proposed for SMBG devices. In October 2011, a group of 45 invited clinicians participated in a closed-door meeting at the 11th Annual Diabetes Technology Meeting to discuss possible standards. They proposed a less stringent baseline set of guidelines for devices (95\% of readings within $\pm 10 \mathrm{mg} / \mathrm{dL}$ below $75 \mathrm{mg} / \mathrm{dL}$ and $\pm 15 \%$ above $75 \mathrm{mg} / \mathrm{dL}$, with $<2 \%$ of readings being $> \pm 15 \mathrm{mg} / \mathrm{dL}$ below $75 \mathrm{mg} / \mathrm{dL}$ or $> \pm 15 \%$ above $75 \mathrm{mg} / \mathrm{dL}$ ) and a method of grading the accuracy of meters for hypoglycemic, euglycemic, and hyperglycemic readings that would be accessible to patients, ${ }^{54}$ e.g. a meter with an accuracy of $\leq 5 \mathrm{mg} / \mathrm{dL}$ for readings between 30 to $75 \mathrm{mg}$ / $\mathrm{dL}$ would receive an ' $A$ ' and an accuracy of $\leq 10 \mathrm{mg} / \mathrm{dL}$ a ' $\mathrm{B}$ ' rating. ${ }^{54}$ This information, currently unavailable to patients, would likely foster a competitive market for meters and encourage continuing improvement in accuracy.

\section{Impact of Tighter SMBG Device Accuracy on Diabetes Care}

With recognition that many commercially available SMBG devices were developed based on original ISO 15197:2003 standards, the ISO advised that a 36-month transition period be instituted before requiring mandatory compliance with the revised 2013 standards. ${ }^{41}$ Clearly, tighter standards will pose challenges for device manufacturers, particularly given the gamut of SMBG result-influencing factors (see Table 2), many of which cannot be controlled by manufacturers; thus, developing SMBG meters with continually improving accuracy may not necessarily be realistic. ${ }^{34}$

One of the driving factors behind the new ISO 15197:2013 criteria is the notion that better performing SMBG devices will result in more accurate insulin dosing, which should translate into better patient outcomes. ${ }^{41}$ However, although this rationale is logical, there currently is no head-to-head evidence demonstrating that differences in analytical accuracy between SMBG meters are associated with differences in clinical outcomes in Type 1 or 2 diabetes. ${ }^{55}$

The revised criteria also do not address the different accuracy needs of various patient groups. For example, noninsulin-treated patients may use SMBG as a general gauge (e.g. to periodically track their overall progress), while women with gestational diabetes or some hospitalized patients require tighter glycemic control and more accurate SMBG monitoring. ${ }^{42,53}$ Although many portable over-the-counter SMBG devices are not intended due to their convenience, ${ }^{53}$ thus, tighter accuracy standards for general SMBG may also benefit the hospital setting. Additionally, since current SMBG is used to calibrate CGM devices, it is imperative that SMBG accuracy be improved.

Recommendations for other SMBG aspects should also be considered. Minimization of patient error could be addressed, e.g. with individually wrapped strips to maintain consistency and eliminate interference from humidity or high temperatures, which could effect SMBG readings. ${ }^{36,55}$ Healthcare providers and patients could also benefit from standardized meter reporting, similar to electrocardiogram readings from different manufacturers. Currently, every meter download looks different, and some reports are difficult to understand or have limited applicability. The need for standardized reporting and data analysis is highlighted in a summary report or approved for hospital use, they are commonly used in this setting 
from an expert panel meeting in March 2012, ${ }^{33}$ and a letter from the FDA. ${ }^{56}$ Moreover, from an end-user perspective, the relative importance of inherent device accuracy versus other features, e.g. durability/ease-ofuse, will vary greatly depending on intended use. ${ }^{55}$ Increased accuracy also needs to be balanced against increased cost. ${ }^{55}$ It is reasonable to anticipate that many patients will resist switching to a new meter, particularly if there is increased monetary or nonmonetary cost (e.g. greater discomfort, larger size of a given sample, or the monitor itself). ${ }^{53}$ Additionally, use of accuracy as a primary criterion for SMBG device selection among patients and caregivers may be confounded by the absence of accuracy data/statistics on product packaging. ${ }^{36}$ Finally, cost is a major healthcare concern, although diabetes drugs, devices, and supplies account for only $28 \%$ of associated costs. ${ }^{3}$ A notification from
Medicare/Medicaid indicated that as of 2014 all strips would be reimbursed at only $\sim \$ 11 /$ box of 50 lancets and strips, which is significantly lower than current reimbursement rates..$^{57}$ If the new ISO 15197:2013 standards lead to significant cost increases their adoption might be poor.

The ongoing evolution of SMBG's has culminated in many unanswered questions and directions for future research. Tighter standards should lead to more accurate SMBG devices; however, patient-focused efforts are required to improve barriers that will not be overcome by even the most accurate meters, including poor adherence to prescribed SMBG frequency and patient error in storage, sampling technique, and reading and interpretation results. Furthermore, standardized reporting and reduced costs may be mandatory with increasing healthcare costs.
1. International Diabetes Federation, IDF Diabetes Atlas, 2012 Update, Brussels, Belgium, 2012

2. International Diabetes Federation, Diabetes Atlas. The Globa Burden. Available at: http://www.idf.org/diabetesatlas/5e/theglobal-burden (accessed March 7, 2013)

3. American Diabetes Association, Economic costs of Diabetes in the U.S. in 2012, Diabetes Care, 2013; Epub ahead of print. The Diabetes Control and Complications Trial Research Group, The effect of intensive treatment of diabetes on the development and progression of long-term complications in insulin-dependent diabetes mellitus, N Eng/ J Med, 1993;329:977-86.

5. The Diabetes Control and Complications Trial/Epidemiology of Diabetes Interventions and Complications (DCCT/EDIC) Study Research Group, Nathan DM, Cleary PA, et al., Intensive diabetes treatment and cardiovascular disease in patients with type 1 diabetes, N Eng/ J Med, 2005:353:2643-53.

6. Hansen MV, Pedersen-Bjergaard U, Heller SR, et al., Frequency and motives of blood glucose self-monitoring in type 1 diabetes, Diabetes Res Clin Pract, 2009;85:183-8. Wood JR, Miller KM, Maahs DM, et al., Most Youth With Type 1 Diabetes in the T1D Exchange Clinic Registry Do Not Meet American Diabetes Association or International Society for Pediatric and Adolescent Diabetes Clinical Guidelines, Diabetes Care, 2013; Epub ahead of print

8. Garg S, Self-monitoring of blood glucose (SMBG), continuous glucose monitoring (CGM), and hemoglobin A1c among T1D Exchange Clinic Registry participants, Presented at: the 5th International Conference on Advanced Technologies \& Treatment for Diabetes; Barcelona, Spain, February 8-11, 2012

9. Miller KM, Beck RW, Bergenstal RM, et al., Evidence of a Strong Association Between Frequency of Self-Monitoring of Blood Glucose and Hemoglobin A1C Levels in T1D Exchange Clinic Registry Participants, Diabetes Care, 2013; Epub ahead of print

10. Kempf K, Kruse J, Martin S, ROSSO-in-praxi: a self-monitoring of blood glucose-structured 12-week lifestyle intervention significantly improves glucometabolic control of patients with type 2 diabetes mellitus, Diabetes Technol Ther, 2010;12:547-53.

11. Davidson MB, Evaluation of self monitoring of blood glucose in non-insulin-treated diabetic patients by randomized controlled trials: little bang for the buck, Rev Recent Clin Trials, 2010;5:138-42.

12. Clar C, Barnard K, Cummins E, et al., Self-monitoring of blood glucose in type 2 diabetes: systematic review, Health Techno Assess, 2010;14:1-140.

13. Cameron C, Coyle D, Ur E, Klarenbach S, Cost-effectiveness of self-monitoring of blood glucose in patients with type 2 diabetes mellitus managed without insulin, CMAJ, 2010;182:28-34.

14. Bonomo K, De Salve A, Fiora E, et al., Evaluation of a simple policy for pre- and post-prandial blood glucose selfmonitoring in people with type 2 diabetes not on insulin, Diabetes Res Clin Pract, 2010;87:246-51

15. Weber C, Kocher S, Neeser K, Bartaskova D, Impact of selfmeasurement of blood glucose on complications of type 2 diabetes: economic analysis from a Czech perspective, Curr Med Res Opin, 2010;26:289-96.

16. Tunis SL, Minshall ME, Self-monitoring of blood glucose (SMBG) for type 2 diabetes patients treated with oral antidiabetes drugs and with a recent history of monitoring: costeffectiveness in the US, Curr Med Res Opin, 2010;26:151-62.

. Tunis SL, Willis WD, Foos V, Self-monitoring of blood glucose (SMBG) in patients with type 2 diabetes on oral anti-diabetes drugs: cost-effectiveness in France, Germany, Italy, and Spain, Curr Med Res Opin, 2010;26:163-75.

18. Benhalima K, Mathieu C, The role of blood glucose monitoring in non-insulin treated type 2 diabetes: what is the evidence? Prim Care Diabetes, 2012;6:179-85.

19. Murata GH, Duckworth WC, Shah JH, et al., Blood glucose monitoring is associated with better glycemic control in type 2 diabetes: a database study, J Gen Intern Med, 2009:24:48-52.

20. Dallosso HM, Eborall HC, Daly H, et al., Does self monitoring of blood glucose as opposed to urinalysis provide additional benefit in patients newly diagnosed with type 2 diabetes receiving structured education? The DESMOND SMBG randomised controlled trial protocol, BMC Fam Pract, 2012;13:18.

21. Schwedes U, Siebolds M, Mertes G, Meal-related structured self-monitoring of blood glucose: effect on diabetes control in non-insulin-treated type 2 diabetic patients, Diabetes Care, 2002;25:1928-32.

22. Guerci B, Drouin P, Grange V, et al., Self-monitoring of blood glucose significantly improves metabolic control in patients with type 2 diabetes mellitus: the AutoSurveillance Intervention Active (ASIA) study, Diabetes Metab, 2003:29:587-94.

23. Barnett AH, Krentz AJ, Strojek K, et al., The efficacy of selfmonitoring of blood glucose in the management of patients with type 2 diabetes treated with a gliclazide modified release-based regimen. A multicentre, randomized, parallelgroup, 6-month evaluation (DINAMIC 1 study), Diabetes Obes Metab, 2008:10:1239-47.

24. Polonsky WH, Fisher L, Schikman $\mathrm{CH}$, et al., Structured selfmonitoring of blood glucose significantly reduces $\mathrm{A} 1 \mathrm{C}$ levels in poorly controlled, noninsulin-treated type 2 diabetes: results from the Structured Testing Program study, Diabetes results from the Structured

25. Davidson MB, Castellanos M, Kain D, Duran $P$, The effect of self monitoring of blood glucose concentrations on glycated hemoglobin levels in diabetic patients not taking insulin: a blinded, randomized trial, Am J Med, 2005:118:422-5.

26. Farmer A, Wade A, Goyder $\mathrm{E}$, et al., Impact of self monitoring of blood glucose in the management of patients with noninsulin treated diabetes: open parallel group randomised trial, BMJ, 2007;335:132.

27. O'Kane MJ, Bunting B, Copeland M, Coates VE, Efficacy of self monitoring of blood glucose in patients with newly diagnose type 2 diabetes (ESMON study): randomised controlled trial, BMJ, 2008;336:1174-7.

28. Allemann S, Houriet C, Diem P, Stettler C, Self-monitoring of blood glucose in non-insulin treated patients with type 2 diabetes: a systematic review and meta-analysis, Curr Med Res Opin, 2009;25:2903-13

29. St John A, Davis WA, Price CP, Davis TM, The value of selfmonitoring of blood glucose: a review of recent evidence, J Diabetes Complications, 2010;24:129-41.

30. American Diabetes Association, Standards of medical care in diabetes-2013, Diabetes Care, 2013;36 Suppl. 1:S11-S66.

31. Garg SK, Smith J, Beatson C, Lopez-Baca B, Voelmle M, Gottlieb PA, Comparison of accuracy and safety of the SEVEN and the Navigator continuous glucose monitoring systems, Diabetes Technol Ther, 2009;11:65-72.

32. Blevins TC, Bode BW, Garg SK, et al., Statement by the American Association of Clinical Endocrinologists Consensus Panel on continuous glucose monitoring, Endocr Pract, 2010;16:730-45.

33. Bergenstal RM, Ahmann AJ, Bailey T, et al., Recommendations for Standardizing Glucose Reporting and Analysis to Optimize Clinical Decision Making in Diabetes: The Ambulatory Glucose Profile (AGP), Diabetes Technol Ther, 2013;15(3):198-211.

34. Garg SK, Hirsch IB, Self-monitoring of blood glucose, Int I Clin Pract Suppl, 2011:1-9.

35. Hirsch IB, Clinical review: Realistic expectations and practical use of continuous glucose monitoring for the endocrinologist, J Clin Endocrinol Metab, 2009;94:2232-8.

36. Ginsberg $\mathrm{BH}$, Factors affecting blood glucose monitoring: sources of errors in measurement, I Diabetes Sci Technol, 2009;3:903-13.

37. Krouwer JS, Cembrowski GS, A review of standards and statistics used to describe blood glucose monito performance, J Diabetes Sci Technol, 2010:4:75-83.

38. American Diabetes Association, Consensus statement on self monitoring of blood glucose, Diabetes Care, 1987;10:93-9.

39. American Diabetes Association, Self-monitoring of blood glucose, Diabetes Care, 1996;19:S62-S66.

40. International Organization for Standardization, ISO 15197. In vitro diagnostic test systems - Requirements for bloodglucose monitoring systems for self-testing in managing diabetes mellitus, May 2003

41. International Organization for Standardization, In vitro diagnostic test systems - Requirements for blood-glucose monitoring systems for self-testing in managing diabetes mellitus. Reference number ISO/FDIS 15197, 2013.

42. Ginsberg BH, We need tighter regulatory standards for blood glucose monitoring, but they should be for accuracy disclosure, J Diabetes Sci Technol, 2010;4:1265-8.

43. Freckmann $\mathrm{G}$, Baumstark $A$, Jendrike $N$, et al., System accuracy evaluation of 27 blood glucose monitoring systems according to DIN EN ISO 15197, Diabetes Technol Ther, 2010;12:221-31

44. Zueger T, Schuler V, Stettler C, et al., Assessment of three frequently used blood glucose monitoring devices in clinical routine, Swiss Med WkIy, 2012;142:W13631.

45. Tack $\mathrm{C}$, Pohlmeier $\mathrm{H}$, Behnke T, et al., Accuracy evaluation of five blood glucose monitoring systems obtained from the pharmacy: a European multicenter study with 453 subjects, Diabetes Technol Ther, 2012;14:330-37.

46. Kimberly MM, Vesper HW, Caudill SP, et al., Variability among five over-the-counter blood glucose monitors, Clin Chim Acta, 2006;364:292-7

47. Chen ET, Nichols JH, Duh SH, Hortin G, Performance evaluation of blood glucose monitoring devices, Diabetes Technol Ther, 2003:5:749-68.

48. Lippi G, Salvagno GL, Guidi GC, et al., Evaluation of four portable self-monitoring blood glucose meters, Ann Clin Biochem, 2006;43:408-413.

49. Freckmann G, Schmid C, Baumstark A, et al., System accuracy evaluation of 43 blood glucose monitoring systems for selfmonitoring of blood glucose according to DIN EN ISO 15197, J Diabetes Sci Technol, 2012:6:1060-75.

50. Kuo CY, Hsu CT, Ho CS, et al., Accuracy and precision evaluation of seven self-monitoring blood glucose systems, Diabetes Technol Ther, 2011;13:596-600.

51. Damiano ER, El-Khatib FH, Zheng H, et al., A comparative effectiveness analysis of three continuous glucose monitors, Diabetes Care, 2013;36:251-9.

52. Leelarathna L, Nodale M, Allen JM, et al., Evaluating the accuracy and large inaccuracy of two continuous glucose monitoring systems, Diabetes Technol Ther, 2013:15:143-9.

53. Klonoff DC, The Food and Drug Administration is now preparing to establish tighter performance requirements for blood glucose monitors, J Diabetes Sci Technol, 2010;4:499-504.

54. Walsh J, Roberts R, Vigersky RA, Schwartz F, New Criteria for Assessing the Accuracy of Blood Glucose Monitors meeting, October 28, 2011, J Diabetes Sci Technol, 2012;6:466-74.

55. Heinemann L, (Analytical) Accuracy of Blood Glucose Meters and Patients: How Do They Come Together?, J Diabetes Sci Technol, 2013;7:1-3.

56. Serrano K, FDA Supports Standardized Reporting and Analysis on CGM Devices, Diabetes Technol Ther, 2013;15:348.

57. Centers for Medicare \& Medicaid Services, Expansion of competitive bidding program will increase competition, maintain quality, and save medicare billions. Available at: http://www.cms. gov/apps/media/press/factsheet.asp?Count er $=4513 \&$ intNumPerPage $=10 \&$ checkDate $=\&$ checkKey $=\&$ srch Type $=1$ \& numDays $=3500 \&$ srchopt $=0 \&$ srchData $=\&$ keywordTyp $\mathrm{e}=$ All \&chkNewsType $=6$ \&intPage $=\&$ showAll $=\&$ p Year $=\&$ year $=\&$ desc $=\&$ cboorder $=$ date $($ accessed March 15, 2013). 